\title{
O julgamento de adolescentes varejistas do tráfico de drogas no Brasil: uma análise de processos judiciais
}

\author{
Luzania Barreto Rodrigues, Ph.D. \\ Universidade Federal do Vale do São Francisco, Brasil* \\ Paulo Cesar Pontes Fraga, Ph.D. \\ Universidade Federal de Juiz de Fora, Brasil**
}

luzania.rodrigues@univasf.edu.br

\section{Resumen (analítico)}

O objetivo do artigo é analisar os processos judiciais relativos ao ato infracional de tráfico de drogas, em Petrolina-PE (2011-2014), com base na revisão analítica das instituições e leis historicamente voltadas para a menoridade, segundo a Theory of Sentencing. Apreciouse o conteúdo social das variáveis legais e extralegais, analisando o efeito cumulativo dos determinantes das sentenças. As decisões judiciais mais encontradas foram extinção processual e absolvição. Medidas socioeducativas de advertência, liberdade e semiliberdade são mais recorrentes que a internação. No entanto, há disparidades das sentenças em casos análogos e imputação de penas análogas em casos díspares. Conclui-se que o sistema penal é produtor e reprodutor de desigualdades sociais e a punição é percebida e utilizada como técnica de controle e transformação de adolescentes pobres apreendidos com pequenas quantidades de drogas.

\section{Palabras clave}

Drogas, adolescentes, justiça e Brasil.

\section{Thesauro}

Tesauro de Ciencias Sociales de la Unesco.

\section{Para citar este artículo}

Rodrigues, L. B., Fraga, P. C. P. (2020). O julgamento de adolescentes varejistas do tráfico de drogas no Brasil: uma análise de processos judiciais. Revista Latinoamericana de Ciencias Sociales, Niñez y Juventud, 18(2), 1-21. http://dx.doi.org/ 10.11600/1692715x.18208

\section{Historial}

Recibido: 13.05.2019

Aceptado: 10.01 .2020

Publicado: 23.05.2020

Información artículo

Esse artigo de investigação científica está baseado na pesquisa de Pós-doutoramento Adolescentes e jovens no plantio ilícito de cannabis e no tráfico de drogas em três cidades da região do Vale do São Francisco: influência das motivações individuais e de elementos estruturais desenvolvida no Programa de Pós-graduação em Ciências Sociais da Universidade Federal de Juiz de Fora, realizado entre março de 2017 e fevereiro de 2018. Área de conocimiento: Ciencias Sociales. Subárea: Sociología 


\section{Legal sentences of adolescents for small-scale drug trafficking in Brazil: an analysis of judicial decisions}

Abstract (analytical)

The purpose of this article is to analyze the legal sentences for drug trafficking offense in Petrolina, a city in the state of Pernambuco, in the period 2011-2014 based on the analytical review of institutions and laws that have historically targeted minorities and the Theory of Sentencing. The social content of legal and extralegal variables was analyzed, analyzing the cumulative effect of determinants for the sentences. The most frequent judicial decisions were procedural extinction and acquittal. Socioeducational measures of warnings, dropping of all charges and suspended sentences are more common than imprisonment. However, there are disparities in sentences for similar cases and the handing down of analogous sentences in disparate cases. It is concluded that the penal system is a producer and reproducer of social inequalities and punishment is perceived and used as a technique for the control and transformation of poor adolescents who are caught with small amounts of drugs.

Keywords

Narcotic Drugs, Teenagers, Justice and Brazil.

\section{Sentencias judiciales contra adolescentes del microtráfico de drogas en Brasil: un análisis de las decisiones judiciales}

Resumo (analítico)

El objetivo del artículo es analizar los procesos judiciales de tráfico de drogas, en Petrolina-PE (20112014) de adolescentes, basado en la revisión analítica de las instituciones y leyes históricamente orientadas hacia las minorías y la Theory of Sentencing. Se apreció el contenido social de las variables legales y extralegales, analizando el efecto acumulativo de los determinantes de las sentencias. Las decisiones judiciales más encontradas fueron la extinción procesal y la absolución. Las medidas socioeducativas de advertencia, libertad y semilibertad son más recurrentes que la internación. Sin embargo, hay disparidades de sentencias en casos análogos e imputación de penalización análogas en casos dispares. Se concluye que el sistema penal es productor de desigualdades sociales y el castigo es percibido y utilizado como técnica de control y transformación de adolescentes pobres incautados con pequeñas cantidades de drogas.

Palavras-chave

Estupefaciente, adolescentes, justicia y Brasil.

Información autoras

[*] Antropóloga. Mestra em Antropologia Social (Universidade de Brasília). Doutora em Ciências Sociais pela Universidade Federal da Bahia. Professora de Antropologia da Universidade Federal do Vale do São Francisco. Correio Eletrônico: luzania.rodrigues@univasf.edu.br (iD) 0000-0002-9707-0018.

[**] Sociólogo. Mestre em Planejamento Urbano e Regional (Universidade Federal do Rio de Janeiro). Doutor em Sociologia pela Universidade de São Paulo. É professor de Sociologia da Universidade Federal de Juiz de Fora. (iD) 0000-0001-9140-8586. Índice H5: 7. Correio Eletrônico: paulo.fraga@ufjf.edu.br 


\section{Introdução}

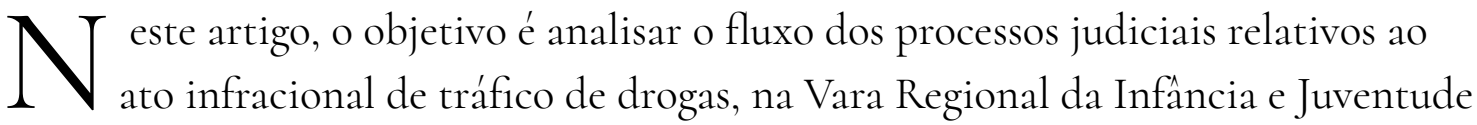
de Petrolina, cidade do Estado de Pernambuco, Nordeste do Brasil, entre os anos de 2011 e 2014. A análise destes processos requereu uma apreciação dos instrumentos jurídicos voltados para crianças, adolescentes e jovens envolvidos em práticas ilícitas e dos respectivos tratamentos instituicionais historicamente dirigidos a esta população, no Brasil, visando sua disciplinarização. Tal apreciação encontra-se na seção 2 deste artigo, intitulada A menoridade e o controle penal da adolescência pobre.

Na seção 3-Metodologia, apresentamos o método utilizado nesta pesquisa documental, que abrange o levantamento dos processos judiciais e a classificação dos dados para posterior análise, com base na apreciação histórica das instituições e leis voltadas para a infância, adolescência e juventude no Brasil e na Theory of Sentencing. Na seção 4 , apresentamos os resultados, 1) descrevendo o número de processos sentenciados, 2) o perfil dos adolescentes processados —cor, sexo, idade, escolaridade, ocupação dos pais e dos próprios adolescentes-, 3) a configuração socioeconômica das suas famílias, 3) o local e as condições concretas da sua apreensão por parte dos agentes policiais, 3) os principais elementos influenciadores das decisões judiciais parciais no curso do julgamento e da sentença e 4) elencando as decisões judiciais mais encontradas e as Medidas Socioeducativas mais recorrentes.

$\mathrm{Na}$ seção 5, discutimos analiticamente os dados descritos e realizamos análises sociológicas das sentenças e do tratamento dispensado à adolescência pobre, visando seu controle social, por parte dos distintos profissionais inseridos no sistema de justiça, a saber: juízes de direito, promotores, assistentes sociais, psicólogos e oficiais de justiça. Por fim, na seção Conclusão, apresentamos como as tomadas de decisão encontram-se influenciadas pela ideia de menoridade e a perpetuam. 


\section{A menoridade e o controle penal da adolescência pobre}

Infância, adolescência e juventude constituíam categorias precariamente distintas da idade adulta até o século XVIII, na Europa e nas suas colônias. Somente no século XIX a infância vai ser tratada como categoria efetivamente distinta (Ariès, 1981). O século XX veio conformar a adolescência como uma fase da vida que mediaria a infância e a maturidade, quando a I Guerra Mundial tornou banal a consciência de juventude, vez que os combatentes jovens se opuseram às velhas gerações de retaguarda.

No Brasil, as noções de infância e adolescência ganharam clivagens jurídicas, morais e de classe, fazendo emergir a categoria «menor», a qual foi atribuída identidade negativa (Rizzini, 1993). No Primeiro instrumento jurídico voltado às crianças e adolescentes, O Código de Menores de 1927, o Juizado de Menores, instituição jurídica a cuidar de casos de crianças e adolescentes em situação irregular ou em conflito com a lei, teria criado um novo padrão de prática jurídica a ser dirigida ao «menor», que passou a ser estudado, examinado e qualificado segundo características morais, físicas, sociais e afetivas. Por isso, antes de ser atendido, «o menor» passava por exames pedagógicos, médico-pedagógicos, médico-psicológicos ou psiquiátricos, «de discernimento» e de «qualificação». Isto foi possivel porque a retroalimentação entre Direito e Psiquiatria permitiu a esta última firmar-se enquanto especialidade médica autônoma, fazendo emergir uma modalidade de saber e de poder que tratou de garantir e justificar, sobretudo por funcionar como um mecanismo de higiene pública, voltando-se para o problema das «populações». O Direito incorporou os frágeis conceitos da psiquiatria — como «periculosidade», «indivíduo perigoso»e «monomania homicida» - em virtude de saber porque punir, isto é, conhecer a natureza do criminoso para tornar justa a punição (Foucault, 2006).

Por meio da categoria «menor», forjou-se uma estratégia institucional que criou um sujeito social tratado como destituído de direitos, indicando que a prática jurídica do Juizado de Menores, por exemplo, não se atinha à concepção estritamente jurídica. Isto é, sua atuação dirigia-se ao denominado «menor», caracterizado não apenas pela idade inferior a 18 ou 21 anos, de acordo com a legislação vigente, mas como ator social pertencente à «família desorganizada», aquela prenhe de atributos negativos, como a vadiagem, a frouxidão moral e a prostituição. Seu ambiente familiar seria, portanto, contaminado pelos maus costumes, a falta de decoro, a imoralidade, o uso de linguagem de baixo calão, assim como sua aparência seria descuidada, suja e enferma. Tratar-se-ia, ademais, de indivíduos de pouca instrução, que anda em companhias suspeitas e trabalha nas ruas para sobreviver (Rizzini, 1993). As noções de família desorganizada ou desestruturada, 
pouco elaboradas e estigmatizantes, ainda hoje têm lugar no imaginário jurídico-penal. Trata-se de um conceito que atrela o ato criminal à biografia dos sujeitos (Foucault, 2006), dando lugar a suposições sobre a vida infracional de crianças e adolescentes, autorizando violências cotidianas como abordagens policiais, revistas, violações de domicílios, confissões forçadas, internação provisória, disciplina prisional e controle pós-disciplinar, como veremos adiante.

A prática jurídica do Juízo de Menores foi sustentada, à época, por aquela Psiquiatria esquadrinhada enquanto medicina do corpo social, na virada do século XIX para o XX (Foucault, 2006). A conversão da infância e da adolescência em «menoridade», no Brasil, deu-se no final do século XIX, e a categoria «menor abandonado» emergiu nas primeiras décadas do século XX, sob influência das teorias sociobiológicas de Nina Rodrigues. Nesse período, os criminologistas da «nova escola penal» elegem categorias sociais que devem ser objeto de «tratamento jurídico diferenciado», a saber: «os loucos», «as mulheres»e «os menores». Combater a infância abandonada converteu-se no projeto civilizador da nação brasileira (Alvarez, 1989). Abundaram, então, as detenções correcionais de «menores», «vadios» e toda sorte de pobres marginalizados, reforçando o controle das classes populares. O Instituto Disciplinar, criado em 1901, institucionaliza a reclusão de menores, segregando-os para, supostamente, regenerá-los. Em 1924, apenas um número diminuto era remetido ao Instituto Disciplinar, sobretudo quando comparado ao alto percentual de detidos sem processo judicial, acusados de contravenções e pequenos delitos patrimoniais e cumprindo o ciclo de detenção e liberação, característico das prisões correcionais (Fausto, 2000). A partir da década de 1930, a reclusão dos «menores» intensifica-se.

O Código de Menores de 1979, que substitui ode 1927, exclui as categorias «menor exposto», «menor transviado», «menor infrator», «menor delinquente», «menor transgressor» e «menor abandonado». Estas são substituídas pelas categorias «menor carente», «menor de conduta antissocial», por entender seus relatores que estas últimas não seriam ofensivas ou estigmatizadoras como as primeiras (Fausto, 2000). No entanto, o «menor carente» e o «menor de conduta antissocial» continuavam sendo apreendidos nas ruas das cidades brasileiras pelo policiamento ostensivo das rondas dos Comissariados de Menores, passando por triagens e investigações realizados pelos Juizados, por Delegacias de Menores e pelos Centros de Triagens das Febem, e, em seguida, retirados da sua vida em grupo (familial ou de rua) e confinados nas instituições ditas de proteção, sob o signo da ressocialização (Silva, 1990). 
Nos anos 1970, o «menor abandonado» - problema social a ser erradicado nas malhas das instituições correcionais- se transformará em «menor de rua», dada sua eloquente presença na cidade. As mudanças retóricas legais não impediram que práticas legais ou extralegais de abuso e de afronta aos direitos humanos contra crianças e adolescentes continuassem a ser praticados. Nos anos 1980, crianças e adolescentes alvo de extermínio eram, via de regra, traficantes varejistas de drogas ilícitas ou aqueles que cometiam pequenos furtos e roubos, que se mantinham livres mediante subornos a policiais militares e sucumbiam quando os valores cobrados por estes eram aviltantes. A exacerbação da violência policial incidia, sobremaneira, contra tais traficantes e os «trombadinhas», que sintetizavam no imaginário social a delinquência urbana (Teixeira, 2012).

$\mathrm{Na}$ década de 1980, a repercussão da violência perpetrada contra crianças e adolescentes fez os movimentos sociais pelos direitos humanos reagirem, propondo uma agenda de debate público acerca das distintas formas de violência sofridas por essa jovem parcela da população, deslocando o foco da delinquência da qual eram acusados. A mobilização desses movimentos foram exponenciadas com a promulgação do Estatuto da Criança e do Adolescente (ECA), que veio reconhecer crianças e adolescentes enquanto «sujeitos de direitos» que devem gozar de proteção integral.

O ECA veio descentralizar o poder sobre as crianças e adolescentes, distribuindo-o e repartindo-o com os Estados e Municípios. Isto é, a antiga política nacional do bemestar do «menor», aprovada em dezembro de 1964, Lei 4513, foi substituída pela Constituição de 1988 e pelo ECA, de 1990, os quais delegaram poderes aos municípios para definir a política peculiar local para a infância e a adolescência (Paula, 2017). É, pois, sob a égide do ECA que são julgados as crianças e os adolescentes em conflito com a lei nas Varas da Infância e da Juventude, em processos judiciais que nos propusemos a analisar aqui.

O que se objetiva esclarecer nessa discussão é o surgimento das categorias «menor»e «criança» no aparato institucional não como meros substantivos, mas, antes, servem para adjetivar a infância, criando uma separação arbitrária entre «infância boa»e «infância ruim» e condenando esta última a um destino perverso. De outro modo, apesar de mudanças substantivas na concepção de atenção e nos direitos de crianças e adolescentes, ainda hoje flui no interior das práticas e dos discursos jurídicos e militares, tais classificações, conforme observamos no fluxo dos processos judiciais examinados, aqueles atinentes ao período de 2011 a 2014, na Vara Regional da Infância e da Juventude da Comarca de Petrolina, Estado de Pernambuco. No presente artigo, o intuito é analisar o fluxo dos processos judiciais relacionados ao comércio varejista de drogas ilícitas nesta 
Vara. Ao cotejar as informações contidas nos Inquéritos, foi possível aceder à descrição da apreensão do adolescente por meio da ronda policial ou da denúncia anônima de tráfico varejista $-\mathrm{e}$ ao perfil dos acusados de tal ato infracional. Também apreciamos o conteúdo social das variáveis consideradas legais - como os níveis de responsabilização dos adolescentes nos argumentos jurídicos, proferidos por promotores, advogados de defesa e pelo juiz de direito, bem como aqueles extralegais, como as classificações morais e discriminatórias arranjadas nos discursos destes mesmos profissionais, a fim de analisar o efeito cumulativo dos determinantes das sentenças.

\section{Metodologia}

$\mathrm{O}$ artigo, portanto, visa analisar os processos jurídicos impetrados contra adolescentes da Vara da Infância e da Juventude de Petrolina, em virtude dos seus atos infracionais análogos ao crime de tráfico de drogas previsto na Lei 11 343/o6, conhecida como a Lei de Drogas.

Após uma seleção, foram encontrados 24 processos correspondentes ao ato infracional análogo ao tráfico, entre os anos de 2011 e 2014. Para facilitar a análise, como os processos não poderiam ser retirados da Vara, foram realizadas cópias digitais da íntegra. Após esta etapa, buscamos classificar e categorizar algumas variáveis visando estabelecer perfis. Usamos as categorias sexo, idade, filiação, cor, escolaridade, profissão, exercício de trabalho lícito, profissão dos pais e bairro de moradia. Visando a classificação, empregamos as seguintes categorias jurídicas: associação para o tráfico, reincidência, antecedente, tipo de pena aplicada, duração da pena, testemunha de acusação, testemunha de defesa, elementos que levaram à identificação do tráfico, direito de apelar em liberdade, tipo de substância psicoativa ilegal, quantidade da substância psicoativa ilegal, réu considerava-se usuário e porte de arma, além de uma categoria extrajurídica: bairro em que o adolescente foi apreendido.

Por meio de uma análise descritiva, exploramos este banco de dados documental procurando identificar as variáveis implicadas no fenômeno do envolvimento de adolescentes com o ato infracional equivalente ao crime de tráfico de drogas. O exame dos dados foi realizado com base na revisão analítica das instituições e leis historicamente voltadas para a infância e adolescência pobres, compreendida enquanto menoridade, segundo a Theory of Sentencing, ou Sentencing Traditional para análise de processos judiciais, 
aplicada em pesquisas de cunho sociocriminológicos, focalizando as possíveis disparidades das penas e nas disposições incorporadas à práxis profissional e social do magistrado (Martins, 2014). A Sentencing Traditional também coteja a desmitificação da neutralidade do juiz de direito nas suas tomadas de decisão, uma vez que considera que seu julgamento é balizado por seu lugar social (Silva, 2015).

Theory of Sentencing é importante instrumento de análise em estudos que buscam investigar sentenças, permitindo uma compreensão ampla das premissas que orientam a prática judicativa (Martins, 2014), levanta questões acerca da possível contribuição do sistema penal na reprodução de preconceitos e de desigualdade socioeconômicas (Fraga et al., 2017). Assim, uma análise fundada somente em estatísticas oficiais apresenta dificuldades em revelar os meandros de decisões judiciais, tendo em vista que estas são produto da ação dos agentes do controle social formal e do modo como estes operam as leis, a moral, os valores e as crenças. Nesse sentido, a análise qualitativa pode ser ilustrada com elementos estatísticos e objetivos, mas devidamente contextualizados e interpretados pelo pesquisador. Ou seja, não se trata de duas abordagens metodológicas que se excluem, mas de duas perspectivas que se complementam.

\section{Resultados}

Foram encontrados 24 processos sentenciados, nos quais foram julgados 27 adolescentes, uma vez que em três dos processos foram ajuizados dois adolescentes. Três jovens do sexo feminino e 24 jovens do sexo masculino, contando entre 14 e 17 anos de idade. Sendo um analfabeto, 19 com ensino fundamental incompleto, cinco com ensino médio incompleto e em três processos não constava a escolaridade do adolescente. Em quinze processos não constava a cor da pele dos processados, oito foram identificados como negros e cinco como pardos. Nenhum adolescente foi identificado como branco. Treze dentre eles exerciam trabalhos lícitos no momento da apreensão policial, todos em postos não profissionalizados, em funções sem grande prestígio social, provavelmente desenvolvidos em condições não adequadas: ajudante de pedreiro, trabalhador rural, auxiliar de eletricista, lavador de carro, carroceiro, badameira e empregada doméstica. O ECA determina que o adolescente somente pode trabalhar na condição de aprendiz de uma profissão reconhecida. Na maioria dos processos, não constava a profissão dos pais, aquelas identificadas foram ajudantes de pedreiro, trabalhador (a) rural e diarista. A maioria não era reincidente ou tinha qualquer passagem pelo sistema policial ou judiciá- 
rio, isto é, do total dos adolescentes, apenas oito deles já se encontravam em conflito com a lei, respondendo processos por homicídio (2), furto (2), tráfico (3), roubo e porte de arma (1).

Nos processos, policiais militares constavam como as únicas testemunhas de acusação, aqueles que fazem a descrição da conduta dos acusados na fase inquisitorial, deixando refletir critérios, valores e ideologias das suas corporações, as quais constituem «subculturas do sistema penal» (Hulsman, 2009, p. 24). É com base em tais formulários, os Boletins de Ocorrência, que o juiz tipifica o crime e infere a prova de autoria, como apontado alhures (Silva, 2015, p. 54). Não há testemunha de defesa nos processos avaliados, excetuando-se duas ocasiões: no primeiro, há uma testemunha sem identificação, constando apenas seu nome; noutro, no qual um adolescente transportava maconha de uma cidade da região para outra, seu conterrâneo, agricultor, atesta a boa índole do rapaz acusado.

As conformações familiais encontradas foram as seguintes: dois pais falecidos, 5 pais desconhecidos, adolescente criado pela mãe sem ajuda do pai, embora o pai fosse reconhecido em seu registro de nascimento e em 20 casos o pai consta no registro. Em nenhum caso a figura paterna acompanhou o filho à delegacia ou ao juízo, a cumprir o papel de responsável legal. Este papel é assumido pela figura materna, excetuando-se dois casos em que foram constituídos responsáveis legais uma irmã e um irmão.

A maioria deles foi apreendida no centro da cidade ou em bairros periféricos onde moram. A apreensão dá-se durante a ronda policial ou através de denúncia anônima. $\mathrm{O}$ roteiro se repete: policiais avistam os adolescentes em «atitudes suspeitas» - as quais nunca são definidas ou descritas-, revistam-nos, encontram pequena quantidade de psicoativos ilícitos e conduzem-nos às suas residências. Lá, segundo depoimento dos policiais, sempre com autorização dos adolescentes ou dos seus familiares, revistam a casa e encontram maior quantidade da substância apreendida com os adolescentes. Curiosamente, em todos os processos, nenhum pai ou mãe teria negado autorização aos policiais para fazer a revista no interior da sua residência. Parece-nos igualmente curioso que em todas as residências tenham encontrado drogas proscritas.

Se o tráfico de drogas constitui crime permanente, o que legitimaria a busca nas residências dos adolescentes sem mandado judicial, não é apenas nestes casos que tal busca se dá (Fraga \& Silva, 2017). Isto é, apesar de estarmos analisando exclusivamente processos judiciais relativos ao ato infracional análogo ao tráfico de drogas, encontramos um processo em que o adolescente foi abordado pela Polícia Militar quando dirigia uma mo- 
tocicleta e se encontrava sem Carteira Nacional de Habilitação. Ato contínuo, em vez de simplesmente autuá-lo, os agentes policiais, sem qualquer argumento mencionado no processo, levaram-no até a sua residência e revistaram-na, com o objetivo de procurar drogas, supostamente encontrando 25 gramas de crack. Tratava-se de um adolescente que exercia a função de auxiliar de eletricista, afrodescendente, contando 17 anos de idade e com ensino médio incompleto. O juiz de direito decretou sua internação provisória - que durou 26 dias-e, ao final, aplicou-lhe a sanção de «advertência» e «liberdade assistida», com acompanhamento de 6 meses da sua vida social, familiar e escolar, com remessa de pedido de relatório semestral sobre seu comportamento para a direção da sua escola e do Centro de Internação Provisória-Cenip.

Enfim, embora esse adolescente tenha declarado que ainda iria começar a vender a substância tornada ilícita, passou quase sete meses em atividades definidas pelo Estado. Uma combinação de «disciplina prisional» com «controle pós-disciplinar», medidas para evitar a reincidência, fator primordial para a boa avaliação dos sistemas socioeducativos (Malvasi, 2012). Noutro caso, o inquérito policial foi aberto porque a polícia foi até a residência do adolescente ao receber «notícia» de que ele agrediu a irmã com cabo de vassoura. Sem nenhum indício de tráfico de drogas — crime permanente, que permite a realização de busca e apreensão nos domicílios sem mandato judicial-, os agentes policiais realizaram busca e apreensão na casa, e teriam encontrado 65 pedras de crack e 231 reais que pertenceriam ao adolescente de 17 anos de idade, ajudante de pedreiro, com ensino fundamental incompleto, morador de bairro periférico, cuja mãe é trabalhadora rural.

Dentre os 24 processos judiciais em apreço, sete deles foram extintos. Dentre as sete extinções processuais, quatro delas se deram em virtude de o adolescente já se encontrar cumprindo medidas socioeducativas em razão de outros atos infracionais, o que leva o juiz a propugnar por unificação das medidas. Outros três processos foram extintos porque os adolescentes não foram encontrados para responder ao processo. Destes, dois foram encontrados dois anos depois, quando já haviam alcançado a maioridade penal: um cumprindo pena por tráfico de drogas e, outra, liberada por ter-se tornado cuidadora da mãe esquizofrênica e da sua filha de três anos de idade, além de estar grávida e trabalhando como catadora de material reciclável, tendo sido considerada «em ressocialização». Trata-se, nos dois casos, de processos que duraram dois anos, demandando vãos esforços do sistema penal.

O oitavo caso de extinção processual é deveras inusitado. O adolescente teria agredido fisicamente sua irmã e guardava consigo 65 gramas de crack. Inicialmente, o pro- 
motor defendeu sua internação provisória, asseverando que «o adolescente praticou atos infracionais extremamente graves e está submetido a intenso risco, ante a possibilidade de inserção em grupo de risco (traficantes e usuários de drogas)». O juiz acolhe o pedido da promotoria, argumentando que houve gravidade na conduta do evento, determinando sua internação provisória e, posteriormente, sentenciando-o à medida de Internação por três anos, a ser reavaliada a cada três meses. Na primeira reavaliação, baseando-se no relatório técnico da Fundação de Atendimento Socioeducativo (Funase), o promotor posicionou-se contra o pedido da defesa, que requereu a liberação do adolescente. Argumentou que «o menor» se envolveu em rebelião no interior da unidade de internação, «realizando atos de vandalismo a exemplo de queima de colchões». O juiz entendeu que o adolescente deveria permanecer internado, «a fim de que se possa aquilatar sua progressão e seu bom desenvolvimento, requisitos indispensáveis para a sua reinserção na sociedade», como se as instituições de internação efetivamente cumprissem tal função social. Na segunda reavaliação, o advogado da Funase, seu defensor, baseado no parecer psicossocial da instituição, pede a progressão da medida socioeducativa, clamando pela medida de Prestação de Serviço à Comunidade, uma vez que o adolescente teria manifestado bom comportamento durante todo o lapso temporal da sua internação e, portanto, deveria «retornar ao convívio social». O juiz, então, sentencia a extinção do processo judicial.

Estes oito processos foram abertos em razão do tráfico varejista de diminuta escala. Num dos casos, o adolescente fora acusado de vender crack a um adulto e teria confessado aos policiais, contudo não portava um grama sequer. Nos demais, adolescentes portariam consigo desde 3 a 33 gramas de crack, ou 3.939 a 21 gramas de maconha. Houve um único caso em que a quantidade de psicoativo ilícito saiu da escala de centigramas e gramas para contar-se por quilo, no qual o adolescente possuía $4.7 \mathrm{~kg}$ de maconha. Os inquéritos policiais e os processos judiciais são iniciados, via de regra, em virtude de os adolescentes encontrarem-se em «atitudes suspeitas», como já citamos, em territórios periféricos, portarem dinheiro trocado e quantidades ínfimas de substâncias psicoativas ilícitas.

Dentre os 24 processos impetrados contra 27 adolescentes, além destes oito supra que foram extintos, 8 adolescentes foram absolvidos, 8 receberam medida de Advertência, Liberdade Assistida e Semiliberdade; e 2 foram condenados à medida de Internação e em um deles a página final da sentença não consta.

Os adolescentes absolvidos foram apreendidos portando de zero a 42 pedras de crack, com exceção de um que detinha 3 gramas de cocaína e 50 reais e outro que portava 
65 gramas de maconha. $\mathrm{O}$ adolescente acusado de vender crack, e que não possuía qualquer quantidade da droga, foi absolvido da acusação de ato infracional análogo ao crime de tráfico por falta de provas materiais. A polícia abriu inquérito que redundou em processo judicial baseando-se em «materialidade indireta». Tratou-se de um adolescente de 15 anos de idade, que exercia trabalho lícito como ajudante de pedreiro. Dois adolescentes que traziam consigo três pedras de crack foram absolvidos em virtude da fragilidade das provas e negação de autoria delitiva, em processos judiciais distintos. Num deles, a Promotora de Justiça entende «que o ato infracional praticado pelo adolescente é de repercussão reduzida, não ocasionando graves consequências, de modo que não se faz necessário o desenvolvimento do processo judicial», solicitando remissão e advertência. Ao que o juiz acatou, entendendo que o ato seria de pequena gravidade. Caso análogo foi de um adolescente acusado de tráfico por estar em companhia de adultos que portavam 42 pedras de crack, no qual o promotor de justiça argumentou que teria ficado provado que $\mathrm{o}$ adolescente não cometeu o ato infracional, em virtude da negação da autoria e do testemunho de um dos policiais afirmando que a droga não se encontrava com o acusado.

As medidas de advertência proferidas pelo juiz de direito podem ou não estar combinadas com medidas complementares, como acompanhamento da vida social, familiar e escolar, Semiliberdade e Liberdade Assistida. Dentre os adolescentes a que foram imputadas medidas de advertência combinadas a outras medidas socioeducativas, dois foram destinados a cumprir medida de Liberdade Assistida, um de Semiliberdade e dois de acompanhamento escolar.

Em três processos distintos, os adolescentes foram absolvidos através do argumento da defesa que não estariam envolvidos em outros atos infracionais, encontrando-se em processo de ressocialização, objetivo maior do ECA, e demonstravam arrependimento. Eles fizeram tráfico varejista de 65 gramas de maconha, 5 e 25 pedras de crack. Nestes casos, a medida de advertência foi somada ao acompanhamento escolar, familiar e social por parte do Centro de Internação Provisória-Cenip-. Nos dois casos em que aos adolescentes foram impetradas medidas exclusivamente de Advertência, os adolescentes haviam atingido a maioridade penal ao final do processo judicial, razão pela qual, de acordo com o juiz de direito, não teriam «capacidade» de cumprir medida socioeducativa. Num dos casos, o adolescente detinha 117 pedras de crack, ou 13.6 gramas; noutro, dois primos, trabalhadores rurais, mantinham consigo 11.34 gramas de crack. $O$ primeiro processo durou dois anos; o segundo, um ano e meio. A incapacidade de cumprimento da medida socioeducativa de advertência atribuída pelos operadores do direito aos adolescentes 
estava perfeitamente em conformidade com a lei, apontando para uma exitosa imagem do judiciário como disciplinador. Frente a casos como estes, é flagrante a urgência de reflexão jurídica e social acerca do tratamento a ser dispensado àqueles que alcançam a idade limite e ficam no limbo, sem a proteção do ECA.

Nos dois casos em que foram combinadas medida de Advertência e medida de Liberdade Assistida durante seis meses, um adolescente transportava 221 gramas de cocaína; o outro, 2 pedras de crack, 12 petecas de cocaína, 1 trouxa de maconha, R\$ 166,oo reais e um celular Nokia C-10o. Nas sentenças, o juiz argumenta que os adolescentes cometeram ato infracional sem violência ou grave ameaça, não havendo maiores danos para a sociedade. No primeiro caso, quando da sua apresentação ao Ministério Público, consta que «o adolescente tem vasta folha de antecedentes de atos infracionais» e responde a outros dois processos judiciais, pelo que o juiz de direito determina a unificação dos autos e das medidas socioeducativas. Durante o andamento do processo, foi-lhe concedido apelar em liberdade sob fiscalização do Centro de Referência Especializado de Assistência Social-Creas-. No segundo caso, a defesa argumentou que o adolescente não era reincidente nem possuía maus antecedentes criminais e que a medida de internação possui princípios próprios a serem seguidos, como a excepcionalidade, de acordo com a qual a internação só é aplicável quando se mostram inadequadas todas as outras medidas socioeducativas, propugnando pela liberdade assistida e asseverando que a experiência de internação poderia suprimir no adolescente «sua ingenuidade», que seria «tomada de assalto». O juiz entende que a medida em meio aberto de Liberdade Assistida seria uma «forma de incentivar os seus estudos e fortalecer seus laços familiares».

Estes dois casos tiveram a mesma sentença, o que demonstra que a reincidência ou os maus antecedentes infracionais não foram decisivos para a determinação da medida socioeducativa a ser imposta, como o juiz e o promotor desta Vara Regional da Infância e Juventude da Comarca de Petrolina argumentaram nos demais processos aqui em análise. Observa-se que a quantidade de substância psicoativa ilícita igualmente não tenha influenciado a decisão judicial acima, uma vez que, em um dos casos que o juiz proferiu a sentença de medida socioeducativa de internação com duração de três anos, o adolescente portava 6 gramas de crack, o que o magistrado considerou «uma quantidade significativa da droga». O julgamento parece ser balizado pela subjetividade do magistrado, circunstancialmente manifesta. O fato de o adolescente não trabalhar ou estudar, além de ser reincidente, é determinante para aquilatar a pena, uma vez que considera agravantes tais quesitos. A mesma medida socioeducativa foi sancionada para um adolescen- 
te que possuía 4.7 quilos de maconha, era reincidente e tinha maus antecedentes infracionais — roubo e posse ilegal de armas—. Via de regra, a reincidência é determinante, ou os antecedentes infracionais, impondo-se a violação da garantia de proibição «de dupla punição pelo mesmo fato» (Karam, 20o8, p. 111). Viola, também, o princípio da isonomia, o qual determina que pessoas em igual situação devem ser igualmente tratadas (Ib. 110). O importante, parece, é punir o adolescente, sua biografia, seu suposto grau de periculosidade e sua conformação familial.

Um adolescente que transportava 3.9 quilos de cannabis de um município do Agreste Pernambucano a outro, prestando serviço de «mula», foi apreendido em flagrante delito e internado provisoriamente em face «da robusta materialidade $\mathrm{da}$ autoria e $\mathrm{da}$ gravidade do ato infracional e sua repercussão social»e, também nas palavras da juíza de direito, em virtude do «risco em potencial de que esse adolescente se enverede pelo caminho obscuro da criminalidade». No bojo do processo, a juíza de direito argumenta constatar que

a conduta do adolescente demonstra a necessidade do afastamento temporário do menor do convívio social e familiar a que está habituado, para que reveja e reeduque sua conduta, possibilitando a reintegração social e as garantias de seus direitos individuais e sociais. Evidencia-se, portanto, a necessidade imperiosa de internação provisória.

Este adolescente foi encaminhado ao Cenip/Funase de Petrolina-PE a fim de ser incluído «em atividades pedagógicas compatíveis com suas aptidões», devendo a instituição apresentar relatório ao Juízo. Doravante, o parecer técnico da equipe multidisciplinar na Funase, contido no processo judicial, atesta que

o adolescente tem bom comportamento, interage com os outros internos e com os funcionários do estabelecimento, tendo demonstrado profundo arrependimento pelo que fez. A conduta desviada do adolescente, embora grave por ser extremamente perniciosa à saúde pública, não merece aplicação de medida socioeducativa de internação, haja vista que o menor não possui antecedentes infracionais, do que se conclui que medida menos severa será capaz de ressocializá-lo e contribuir para a reestruturação do seu caráter, sobretudo diante da demonstração de arrependimento do jovem.

O advogado de defesa propugnou por medida de semiliberdade. O promotor concordou com a defesa. A juíza de direito o submeteu à medida de semiliberdade por tempo indeterminado, com avaliação a cada seis meses. Aqui, parece ficar patente que «o adolescente em conflito com a lei é ao mesmo tempo visto como perigoso e vulnerável, e 
que a demonstração de arrependimento constitui a senha para escapar da internação, o que este jovem personagem dá ares de perceber e acionar.

\section{Discussão}

Atualmente, tudo parece transcorrer de acordo com a lei. Os policiais apreendem crianças e adolescentes, conduzem-nos às delegacias e, ato contínuo, à Vara da Infância e da Juventude. No entanto, tais apreensões continuam dando-se, exclusivamente, em territórios de bairros periféricos da cidade, com vistas ao estrito controle desses espaços (Alvarez, Fraga, \& Campos, 2017) e desses indivíduos percebidos tão somente como pobres de pouca instrução, oriundos das nomeadas famílias desestruturadas, que andam em companhias classificadas como suspeitas e praticando ações, também, duvidosas, como aparecem na totalidade dos processos aqui analisados. Esses dados parecem indicar seletividade da justiça e do sistema policial (Boiteux, 2015), dedicados a perseguir, julgar e condenar adolescentes com o mesmo perfil socioeconômico. Nas periferias urbanas de pequenas, médias e grandes cidades brasileiras, os agentes policiais parecem seguir avistando as figuras jurídicas criadas por legislações ultrapassadas, o menor infrator, o menor delinquente.

Parte dos operadores do direito parecem ainda não ter incorporado ou possuem dificuldades em atualizar suas práticas profissionais com o estabelecido no ECA, instrumento de proteção integral. Sua condição é ontológica. E a terminologia que estigmatiza é encontrada nos inquéritos policiais e nos testemunhos de acusação, em juízo, dos soldados que os apreendem. A terminologia menor, incrustada no seu linguajar, encontrase deveras incorporada na conduta profissional de tais agentes. Por suas mãos, os adolescentes em conflito com a lei continuam sendo menores infratores. Eles são revistados e, encontrando-se ou não em posse de drogas proscritas, devem guiar os soldados até sua residência e, lá, «permitirem» o procedimento de busca e apreensão. Curiosamente, a «permissão» é invariavelmente concedida pelo «menor» ou por sua família. Chamou-nos a atenção esse procedimento quase padrão de conduta policial. Não fica claro em que condições acontecem, porque sempre se dirigem a casa do adolescente para vasculhá-la.

O magistrado, por sua vez, limita-se a indicar os termos da medida - como a inserção na escola, no trabalho e na família, a eliminar seu estigma de perigoso e infrator que lhe foi imprimido no próprio processo judicial-, com vistas a uma adequação a um pa- 
drão socialmente aceito, sem atentar às condições objetivas para alcançá-la, o que já foi verificado em outros estudos em varas da infância e juventude (Sartório \& Rosa, 2010).

Ao examinarmos os processos judiciais, verificamos que assistentes sociais, psicólogos, advogados, oficiais de justiça e juízes de direito não escapam a esta ideologia. Verifica-se a persistência do movimento pendular entre as noções de adolescência e menoridade, a contaminar o corpo institucional, mormente seu linguajar. O uso do termo menor é tão recorrente que chega a ser usado mesmo para designar documento jurídico, como o Termo de Audiência de Ouvida Prévia de Menor. A categoria menor, portanto, é uma importante designação política, pois define ações, distingue sujeito e imprime punições (Foucault,2006). Enfim, a adjetivação da adolescência pobre é uma constante, concorrendo para transformar sua prática circunstancial em destino indelével (Alvarez et al., 2017).

O destino inevitável do adolescente apreendido é selado, na prática, quando um ato é julgado duas vezes, isto é, quando um ato infracional passado pode influenciar sobremaneira a decisão judicial, na forma de reincidência ou antecedentes criminais. Sem dúvida, os procedimentos judiciais distam das práticas policiais no que concerne aos óbvios juízos de valor impregnados nestas últimas. Suas decisões são balizadas, mais propensas à extinção processual —embora, amiúde, em razão da unificação das medidas socioeducativas- e à absolvição; as medidas socioeducativas de advertência, liberdade e semiliberdade são mais recorrentes que a medidas mais duras, como a de internação. No entanto, não são neutras ou universais, vide as disparidades das sentenças em casos análogos e a imputação de penas análogas em casos díspares (Martins, 2014).

De modo geral, o sistema penal brasileiro reforça as desigualdades sociais (Hulsman, 2009; Hulsman \& Celis, 1993), despende de esforços profissionais que poderiam estar direcionados à resolução de crimes ou atos infracionais violentos. A maioria dos processos decorridos entre 2011 e 2014, na Vara, em Petrolina, foram abertos contra adolescentes que portavam quantidades muito pequenas de psicoativos ilícitos, em territórios urbanos periféricos. Outros estudos mostram que essa prática não é isolada nos tribunais brasileiros (Boiteux, 2015; Campos \& Alvarez, 2017). Tais adolescentes não têm seus direitos assegurados no rito do direito porque o sistema penal coaduna com o rudimentar discurso público acerca da guerra às drogas, na falsa polarização entre crime e sociedade, bandido e trabalhador, legal e ilegal (Malvasi, 2012).

As violações de direitos são recorrentes, forças policiais e judiciárias costumam abrir inquéritos e processos judiciais improcedentes (Campos \& Alvarez, 2017), como é o 
caso de certo rapaz que fora preso quando avistado jogando no chão 3,5 gramas de maconha e se declarara usuário da substância.

Juízes de direito e promotores de justiça aceitam e defendem o trabalho infantil e juvenil irregular ao alegarem, no bojo das sentenças, seu suposto caráter pedagógico e moral, pois manteria crianças e adolescentes afastados das vias públicas, nas quais estariam expostos à mendicância, à promiscuidade e a ações delituosas (Lourenço, 2014).O trabalho precoce, ilegal segundo a legislação brasileira, paradoxalmente é legitimado por autoridades judiciárias, deixando de ser percebido em sua negatividade, mas, ao contrário, visto como instrumento de prevenção da marginalidade e da delinquência: «O ideal passa a ser o aprendizado de uma profissão, mesmo que esta seja precária, insegura e que represente riscos à saúde da pessoa em desenvolvimento» (Lourenço, 2014, p. 302) e ao seu próprio desenvolvimento intelectual e profissional. Na perspectiva dessa racionalidade, compreende-se que as situações ilegais e irregulares vivenciadas por adolescentes pobres figuram como profiláticas na prevenção da criminalidade. Nesse sentido, parece que se fecha o ciclo da reprodução da pobreza: trabalhando e frequentando uma escola precária, crianças e adolescentes tornar-se-ão adultos que terão necessidade de contar com o trabalho infanto-juvenil da sua prole.

De acordo com o art. 5, inciso 11, da Constituição Federal, buscas em residências devem ser realizadas mediante autorização da Justiça. Entretanto, a Lei 11 343/o6, em seu artigo 33, define que manter entorpecentes em depósito constitui delito permanente. De acordo com o Supremo Tribunal Federal, «o artigo 330 do Código de Processo Penal considera como situação de flagrância aquele que estiver cometendo crime permanentemente». Foi com base nestes argumentos que a Suprema Corte brasileira definiu que a polícia pode apreender drogas nas residências sem mandato judicial (Galli, 2015). As buscas policiais são feitas, via de regra, em casa de pessoas pobres, periféricas e com baixa instrução, com históricos de violação de direitos e sem condições de reagir a qualquer arbítrio policial. É o que demonstra eloquentemente os dados levantados em outro trabalho na Vara Regional da Infância e Juventude da Comarca de Petrolina, Pernambuco, ora em análise, corroborados por aqueles encontrados na Vara da Infância e da Juventude em Juazeiro (Rodrigues, Ribeiro, \& Fraga, 2017). Ademais, esta decisão da Suprema Corte data de 2015, ano posterior àqueles relativos aos processos judiciais que compõem nosso banco de dados (2011-2014). Isto é, antes mesmo da decisão da Suprema Corte, as buscas e apreensões policiais sem mandato judicial, nas residências desses adolescentes eram corriqueiras. 
Os argumentos de acusação, decisivos para a sentença a ser postulada pelo juiz de direito, baseiam-se em quesitos como a quantidade da droga encontrada e em outros itens que o adolescente mantenha em posse quando apreendido - geralmente, dinheiro trocado; na gravidade do fato- se cometido ou não mediante grave ameaça ou violência; na capacidade de o adolescente cumprir a medida proposta; a demonstração de arrependimento por parte do adolescente, sua busca e inserção no processo de ressocialização, aí incluído bom comportamento durante a internação provisória, retomada dos estudos formais e a inserção em trabalho lícito.

O que se pode notar é uma tensão entre proteção, controle, direito, moral e segurança pública, transparecendo mais a preocupação com a defesa da sociedade que do adolescente. Além disso, resta evidenciado que o adolescente tem que primeiro passar pela experiência infracional, ser inserido no sistema socioeducativo e, por último, ter acesso aos programas sociais, numa clara inversão das medidas de proteção social, em flagrante inobservância aos seus direitos sociais previstos em lei, como já apontaram Silva (2005) e Schuch (2005).

\section{Conclusão}

Promulgado em 1990, o ECA reconheceu crianças e adolescentes enquanto «sujeitos de direitos» que deveriam ser protegidos pelo Estado e seu sistema de polícia e justiça, em vez de perseguidos. Ao serem apreendidos, então, deveriam ser imediatamente apresentados ao juiz de direito da Vara da Infância e da Juventude, donde seriam asseguradas sua ampla defesa e sua presunção de inocência, no curso de um processo judicial. Não obstante, como foi demonstrado aqui, o protocolo é parcialmente observado pelos agentes do sistema judicial e inobservado pelos agentes policiais. Desde a dimensão discursiva, nota-se a perseverança de classificações que estigmatiza esta jovem população, facilmente observadas no fluxo dos processos judiciais examinados.

A dimensão discursiva guarda correspondência com a prática policial e judicial, orientada pela vaga e eternizada ideia de «atitude suspeita» de crianças e adolescentes radicados em territórios periféricos, o que resulta no controle disciplinar da infância e adolescência pobres pelo sistema de justiça criminal durante os longos períodos de cumprimento da medida de advertência, que chegam a durar dois anos. Via de regra, os agentes judiciais aparentemente agem em observância à lei, o que sela seu êxito disciplinador, 
não obstante desprovido de reflexão jurídica acerca das implicações sociais deste mesmo controle.

Reincidência, antecedentes infracionais, quantidade de drogas apreendida, inserção em escola formal e em trabalho, formal ou informal, são comumente considerados para a apuração da medida educativa, sendo os três primeiros quesitos considerados agravantes e os dois últimos, atenuantes. Mas há exceções e disparidades, o que aponta para a influência da subjetividade do magistrado na tomada de decisão, para a constante duplicação da punição pelo mesmo fato e para a inobservância do princípio da isonomia. Disso resulta a perpetuação da divisão entre menoridade e infância e adolescência inserida e protegida, com acentuada influência de uma política de drogas esboçada e mantida para punir os pobres e isentar o Estado de elaborar e implementar políticas públicas promotoras de bem-estar.

\section{Referências}

Alvarez, M. C. (1989). A emergência do Código de Menores de 1927: uma análise do discurso jurídico e institucional da assistência e proteção aos menores [Tese de mestrado no publicada]. Universidade de São Paulo.

Alvarez, M., Fraga, P. C. P., \& Campos, M. (2017). Perspectivas atuais sobre políticas, produção, comércio e uso de drogas: apresentação ao dossiê «Drogas e Sociedade em uma perspectiva comparada». Tempo Social, 29(2), 1-14. https://doi.org/ 10.11606/0103-2070.ts.2017.133303

Ariès, P. (1981). História Social da Criança e da Família. LTC.

Boiteux, L. (2015). El antimodelo brasileño: prohibicionismo, encarcelamiento y selectividad penal frente al tráfico de drogas. Nueva Sociedad, 255, 132-144.

Campos, M., \& Alvarez, M. (2017). Pela metade: implicações do dispositivo médicocriminal da «Nova» Lei de Drogas na cidade de São Paulo. Tempo Social, 29(2), 45-73. https://doi.org/10.11606/0103-2070.ts.2017.127567

Fausto, B. (2000). Crime e Cotidiano: a criminalidade em São Paulo (1880-1924). Edusp. Foucault, M. (2006). Ditos e escritos: ética, sexualidade e política. Forense Universitária. Fraga, P. C. P., \& Silva, J. K. (2017). A participação feminina em mercados ilícitos de drogas no Vale do São Francisco, no Nordeste brasileiro. Tempo Social, 29(2), 135-157. https://doi.org/10.11606/0103-2070.ts.2017.128528 
Fraga, P. C. P., Silva, J. N., \& Martins, R. S. (2017). Mujeres y criminalidad: un estudio sobre a participación de las mujeres en el cultivo de cannabis en el Vale do São Francisco, Brasil. Estudios Sociológicos, 35(1), 547-570. https://doi.org/10.24201/ es.2017v35n105.1498

Hulsman, L. A. (2009). Perspectiva abolicionista: apresentação em dois tempos —qual abolição? Verve. Revista Semestral Autogestionária do Nu-Sol, 15(1), 18-32.

Hulsman, L. A., \& Celis, P. (1993). Penas Perdidas: o sistema penal em questão. Luam Editora.

Galli, M. (2015). Flagrante Delito: polícia pode apreender drogas dentro de casa sem mandato, decide Supremo. Conjur.

Karam, M. L. (2008). A Lei 11 343/06 e os repetidos danos do proibicionismo. En B. Labate (Ed.), Drogas e Cultura: novas Perspectivas. Edufba.

Lourenço, E. A. de S. (2014). Reestruturação produtiva, trabalho informal e invisibilidade social de crianças e adolescentes. Serviço Social e Sociedade, (118), 294-317. https://doi.org/10.1590/So101-66282014000200005

Malvasi, P. A. (2012). Interfaces da vida loka: um estudo sobre jovens, tráfico de drogas e violência em São Paulo [Tese de doutorado, Universidade de São Paulo]. Biblioteca Digital USP. https://doi.org/10.11606/t.6.2012.tde-09032012-132410

Martins, R. S. (2014). Estupro de criança e adolescentes e a desigualdade nos tribunais: uma análise dos processos judiciais. NEA.

Paula, L. de (2017). Punição e cidadania: adolescentes e liberdade assistida na cidade de São Paulo. Alameda Casa Editorial.

Rizzini, I. (1993). O elogio do científico: a construção do «menor» na prática jurídica. Em I. Rizzini (Ed.), A criança no Brasil hoje: desafio para o terceiro milênio. Edusu.

Rodrigues, L. B., Ribeiro, M da S., \& Fraga, P. C. P. (2017). O envolvimento de adolescentes no tráfico de drogas em Juazeiro — norte da Bahia: uma análise do fluxo dos processos judiciais da Vara da Infância e da Juventude. Teoria e Cultura, 12(1), 241-252. Sartório, A. T. \& Rosa, E. M. (2010). Novos paradigmas e velhos discursos: analisando processos de adolescentes em conflito com a lei. Serviçio Social \& Sociedade, (103), 554-575. https://doi.org/10.1590/So101-66282010000300008

Schuch, P. (2005). Práticas de justiça: uma etnografia do campo de atenção ao adolescente infrator no Rio Grande do Sul, depois do Estatuto da Criança e do Adolescente [Tese de doutorado no publicada]. Universidade Federal do Rio Grande do Sul.

Silva, A. F. do A. (1990). A Mutação Judicial. En Brasil Criança Urgente (Ed.), A Lei 8069/9o: o que é preciso saber sobre os novos direitos da criança e do adolescente (pp. 114-127). Columbus Cultural. 
Silva, M. O. (2005). O controle sócio-penal dos adolescentes com processos judiciais em São Paulo: entre a «proteção» e a «punição» [Tese de doutorado no publicada]. Pontifícia Universidade Católica de São Paulo.

Silva, J. N. (2015). Mulheres no tráfico de drogas: um estudo sobre os determinantes da condenação na cidade de Juiz de Fora, Minas Gerais. Em P. C. P. Fraga (Ed.), Mulheres e Criminalidade (pp. 47-80). Letra Capital.

Teixeira, A. (2012). Construir a delinquência, articular a criminalidade: um estudo sobre a gestão dos ilegalismos na cidade de São Paulo [Tese de doutorado no publicada]. Universidade de São Paulo. 